\title{
Modelling the impact of energy intensity on the economic and environmental costs of internally plumbed rainwater tanks systems
}

\author{
$\underline{\text { R. Siems }}^{\text {a }}$, O. Sahin ${ }^{a}$ and R.A. Stewart ${ }^{a}$ \\ ${ }^{a}$ Centre for Infrastructure Engineering and Management, Griffith University, Queensland, Australia, \\ Email: raymond.siems@griffithuni.edu.au
}

\begin{abstract}
Australian capital cities are forecast to face decreased average annual rainfall by 2030 under mid-emissions climate scenarios. With two-thirds of Australia's population already residing in these growing major cities, urban water resources pressure will undoubtedly increase in the years ahead. Methods to augment traditional reservoir based water supply will be required to maintain water security.
\end{abstract}

Internally plumbed rain water tank systems (IPRWTs), supplying water at a decentralised level, are one potential alternate supply source. Incentive schemes and legislation have seen IPRWTs become increasingly prevalent in metropolitan areas since widespread drought from 2000-2009. For example in Queensland water savings targets were mandated for all newly constructed homes. The most common means of meeting these targets was through the use of IPRWTs, which when installed were required to supply garden irrigation, clothes-washers and cistern flush events.

Studies to date have been focused on maximising potable savings, such that little research has investigated the energy intensity and greenhouse gas emissions associated with the operation of IPRWTs. This is a worthy consideration given that they are typically thought of as green, sustainable solutions.

This paper examines the energy intensity and greenhouse gas cost of IPRWTs under a number of modelled usage scenarios, utilising high-resolution end-use level data from a recently conducted IPRWT monitoring study in South East Queensland. This modelling, facilitated through the use of specialised software, MATLAB and spread-sheet software, has determined the average annual energy consumption of IPRWTs, taking into account the effect of climatic conditions on water consumption. This energy consumption leads to electricity and carbon based costs to homeowners and the general community, which have been quantified at an end-use level.

In the interests of system optimisation, the net economic and environmental impacts of configuration changes to IPRWTs have been considered, such as not plumbing in toilet cisterns. For standard 2.8 person households preliminary evidence indicates that based only on operational costs, more end-uses are preferable, due to higher yields. However, when plumbing and environmental costs are taken into account it has been found that it may be worthwhile to plumb in only the most energy efficient rainwater end-uses (irrigation and clothes washing).

For larger households, or those consuming large volumes of water in regular irrigation, energy intensity of water supply can be significantly lowered by only plumbing in efficient end-uses, while yearly water savings (from avoided mains costs) fall only by a small margin. For retrofitters and new home builders the extra cost incurred when plumbing in toilet cisterns to rainwater supply should be considered. Existing system owners should note the large increase in system energy intensity when small leaks develop from poor maintenance, usually from toilet cisterns, as this can lead to significantly greater economic and environmental costs over the lifetime of a rainwater system and reduce the viability of cistern end-uses.

Keywords: Rainwater tanks, energy intensity, water supply systems, greenhouse gas emissions 
Siems et al., Impact of energy intensity on the economic and environmental costs of rainwater tank systems

\section{INTRODUCTION}

Australia may appear abundant in its water supply; only utilising approximately $5 \%$ of its total renewable freshwater resources (OECD, 2006). However, due to an uneven distribution of population, with $85 \%$ of citizens living in coastal regions (DCC, 2009), many regions extract more than $50 \%$ of total annual renewable supply (Hatton et al., 2011).

Pressure on potable water resources in urban areas is expected to increase in the years ahead. Population growth of up to 30\% forecast by 2021, with the majority of this growth expected in urban areas (Pink, 2012). While the CSIRO (2011a) predicts that under-mid emissions climate change scenarios all Australian capital cities will face decreased average rainfall by 2030 . Thus, there is a clear need to augment traditional reservoir based water supply with alternative sources, to maintain water security in urban areas.

Internally plumbed rain water tank systems (IPRWTs), supplying water at a decentralised level, are one potential solution. Incentive schemes and legislation have seen IPRWTs become increasingly prevalent in metropolitan areas since widespread drought from 2000-2009 (CSIRO, 2011b). For example in Queensland water savings targets of between 16 and $70 \mathrm{~kL} / \mathrm{hh} /$ year, depending on region, were mandated for all newly constructed homes under Queensland Development Code Mandatory Part 4.2 (QDC MP 4.2) (DIP 2009). The most common means of satisfying this legislation was through the use of IPRWTs, which when installed were required to supply garden irrigation, clothes-washer and cistern flush events. However it has been found these water savings targets were overly optimistic, with typical water savings from IPRWTs in South-East Queensland between 40 to $50 \mathrm{~kL} / \mathrm{hh} /$ year range (Beal et al., 2012).

Water supply systems are not only impacted by climate change, they also contribute to it through the consumption of energy (Flower et al., 2007). This energy-water-climate nexus means that water supply systems selected to augment traditional reservoir based supply must both provide water and consume energy efficiently. IPRWTs studies to date have been focused on maximising potable savings, such that little research has investigated the energy intensity and greenhouse gas (GHG) emissions associated with the operation of IPRWTs (Stewart, 2011; Beal et al., 2012). This is a worthy consideration given that they are typically thought of as green, sustainable solutions.

This paper examines the economic and environmental costs derived from the operation of IPRWTs using an end-use level model. This model is informed with energy intensity data from a recently completed 19 home end-use level monitoring study conducted by the research team in Gold Coast City (GCC), the first of its kind (Siems et al., 2013). The model allows a number of usage scenarios to be compared, under various water, energy and carbon price levels. Analysis at end-use resolution (i.e. energy intensity varies based on the nature of a water usage event) allows for greater optimisation of IPRWTs and clearer assessment of their merits as an alternative water supply source.

\section{GATHERING INPUT DATA}

The following section details the research undertaken to gather input data for the end-use level IPRWTs model.

\subsection{In Home Monitoring Study}

Initially, a two week pilot study (Talebpour et al., 2011) involving 5 homes was conducted to validate the effectiveness of an experimental set-up. The data collected was required to be reliably disaggregated into individual events and classified under one of the four QDC MP 4.2 mandated IPRWTs end-uses (cistern fullflush, cistern half-flush, clothes washer and irrigation events). This was successful and the same method was selected for a larger study involving 19 homes located around GCC, of which this modelling is an extension.

All 19 systems selected were from homes constructed since the inception of the QDC MP 4.2 legislation in 2007 , with a $5 \mathrm{~kL}$ tank and $100 \mathrm{~m}^{2}$ of plumbed roof area as minimum (QG, 2007). All of the 19 IPRWTs possessed a fixed speed pump, which was by far the most common type encountered when searching for participants. Four models and three manufacturers were represented within the sample. 


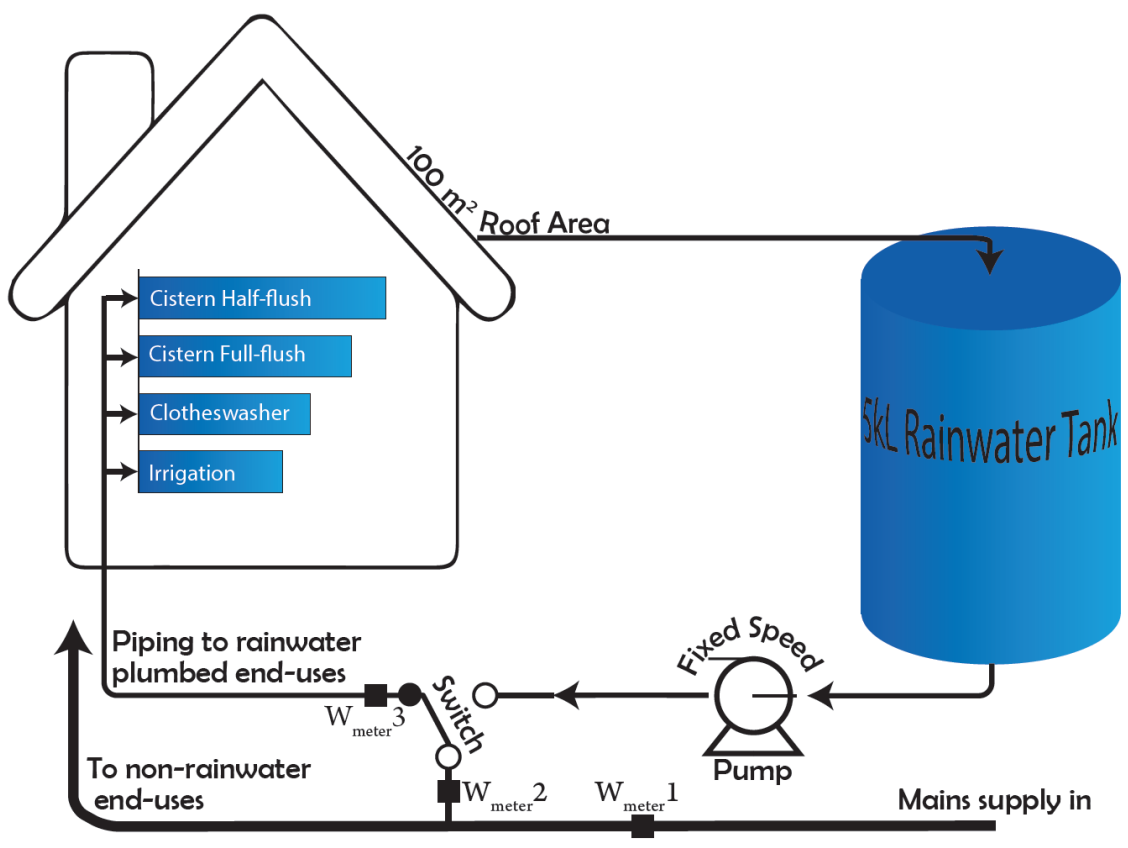

Figure 1. IPRWTs schematic as under QDC MP 4.2.

Three high resolution water meters and one electricity meter (to record pump electricity consumption) were installed in each home, collecting data at 5 second intervals from November 2012 until the end of April 2013 (Figure 1). Two data loggers (one for mains supply and one for all other meters) wirelessly transmitted usage data through cellular networks to Griffith University's Smart Meter Information Portal. Flow trace analysis was then conducted using Trace Wizard (Aquacraft, 1997), in conjunction with stock and appliance survey information to increase classification accuracy. This process is more extensively outlined in other works by the research team (Beal et al., 2011; Willis, 2011; Siems et al., 2013). After classification, water usage events and corresponding energy usage data were transferred to a database and analysed using spread-sheet software.

\subsection{End-use Energy Intensities}

Presented in Table 1 are the mean energy intensities found for each of the four mandated end-uses under QDC MP 4.2, from a population of 1,210 individual events. In order to arrive at these mean values all event data under each end-use was aggregated and divided by the total number of events in that category. This best reflects how these systems are performing from a wider perspective based on the data available (as opposed to taking the mean of the mean from each system).

This was the first known in home empirical study conducted at an end-use level. Limited modelling has been carried out at this resolution (such as Retamal et al. (2009)), along with a single lab home study for toilet end-use (Cunio and Sproul, 2009).
Table 1. Mean end-use energy intensities from aggregated event data population.

\begin{tabular}{lc}
\hline End-use & $\begin{array}{c}\text { Energy } \\
\text { Intensity } \\
\text { Category }\end{array}$ \\
\hline Cistern Half-flush & $\mathbf{1 . 8 0}$ \\
\hline Cistern Full-flush & $\mathbf{1 . 5 5}$ \\
\hline Clothes Washer & $\mathbf{1 . 2 5}$ \\
\hline Irrigation & $\mathbf{1 . 0 2}$ \\
\hline
\end{tabular}

\subsection{Standby Consumption / Non-event Consumption}

While processing data it was observed that electricity usage was occurring in some systems at times when no water was supplied. In order to quantify this over the monitoring period, a script was written to remove all electricity usage associated with water supply events, which was deemed at 15 seconds either side of recorded water consumption. The remaining usage in the data feeds
Table 2. Total system energy intensity and NEC results from 19 home sample.

\begin{tabular}{lccc}
\hline & $\begin{array}{c}\text { In directly } \\
\text { supplying } \\
\text { rainwater } \\
(\mathbf{k W h} / \mathbf{k L})\end{array}$ & $\begin{array}{c}\text { Total } \\
\text { system } \\
\text { intensity } \\
(\mathbf{k W h} / \mathbf{k L})\end{array}$ & NEC \\
$\mathbf{( \% )}$ \\
\hline Group 1 & 1.28 & 1.28 & 0.05 \\
\hline Group 2 & 1.44 & 2.05 & 29.7 \\
\hline Total & 1.34 & 1.56 & 13.6 \\
\hline
\end{tabular}


Siems et al., Impact of energy intensity on the economic and environmental costs of rainwater tank systems

represented this non-event electricity consumption (NEC).

Preliminary discussions with plumbing professionals and householders indicate that leaky toilet cisterns are the primary cause of this usage. Leaks of less than $2 \mathrm{~L}$ /hour are not detectable by the Actaris CTS-5 water meters utilised (Huang and Stewart, 2011), but would require regular re-pressurisation of the system. Thus no water usage is recorded, but energy is consumed.

Analysis revealed that of the 19 homes, 11 showed negligible NEC $(<0.1 \mathrm{kWh}$ per month). However, 8 systems exhibited very significant amounts of NEC. Thus, the homes have been considered in these two distinct groups in Table 2, with a combined total also found.

\section{SCENARIO MODELLING}

Following the completion of the 6 month study an end-use level IPRWTs model has now been developed, informed with empirically derived data. The goal of the model being to analyse the impact of energy intensity on IPRWTs viability under different system configurations, usage habits and resource price schemes.

\subsection{Model Development}

A MATLAB (MathWorks, 2012) based model was developed to simulate the operation of a rainwater tank. The tank volume for a given day is determined from a mass balance equation, presented in Equation 1.

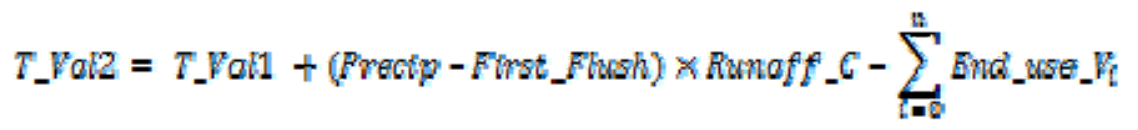

where: $\quad$ T_Vol2 = tank volume for current day $\left(\mathrm{m}^{3}\right)$

$T \_$Vol1 = tank volume for previous day $\left(\mathrm{m}^{3}\right)$

Precip = precipitation for current day $\left(\mathrm{m}^{3}\right)$

First_flush $=$ roof and first flush system losses $\left(\mathrm{m}^{3}\right)$

Runoff_C $=$ roof runoff coefficient

End_use_V $=$ volume of water usage for given end-use on current day $\left(\mathrm{m}^{3}\right)$

An overflow before yield approach was taken to remain conservative, with yield for any day only taken from what is available at the start of that day. The energy consumption of the IPRWTs on any given day is calculated as shown in Equation 2.

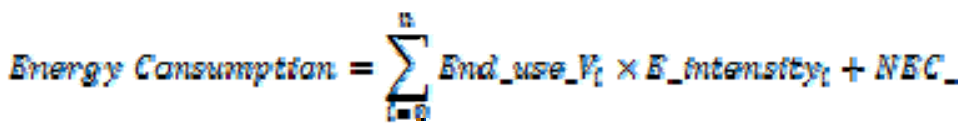

where: End_use_V=volume of water usage for given end-use on current day $\left(\mathrm{m}^{3}\right)$

E_intensity = energy intensity of end-use event type $\left(\right.$ Table 1) $\left(\mathrm{kWh}^{\mathrm{m}} \mathrm{m}^{3}\right)$

$N E C_{-}=$non-event electricity consumption for current day ( $\left.\mathrm{kWh}\right)$

Previously developed rainwater tank models have been focused on water yields, with only the magnitude of daily tank water usage relevant. However from an end-use energy intensity perspective, the breakdown of daily tank water usage is important, as this will influence the energy consumption. It is has been found that irrigation varies significantly with climatic conditions, particularly precipitation (Willis, 2011), which required reciprocation in the model.

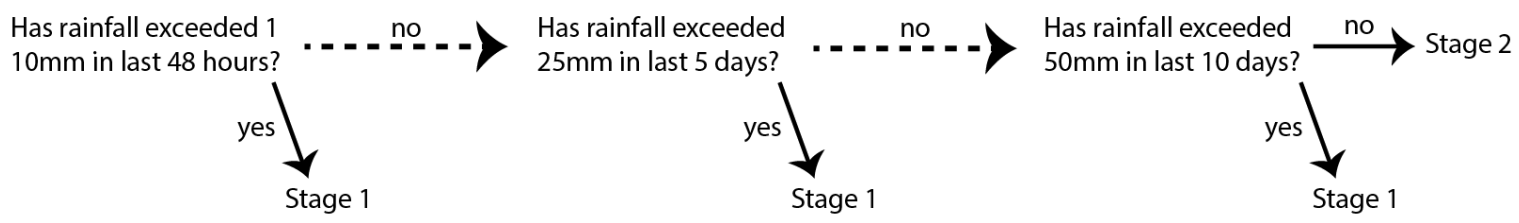

Figure 2. Flowchart governing change in irrigation habits with precipitation. 
A two stage, multi criteria approach was employed to simulate changes in daily irrigation volumes with recent precipitation, illustrated in Figure 2. Stage 1 and $2(\mathrm{~L} / \mathrm{p} / \mathrm{d})$, as well as rainfall threshold values $(\mathrm{mm})$ are user determined. Accounting for this will also more accurately predict annual yields than previous rain tank models.

\subsection{Input Parameters}

Table 3 details the base input parameters inserted into the model. The 20 years of historical rainfall data was selected from the Coombabah Wastewater Treatment Plant weather station, due to its central location in GCC.

The runoff coefficient accounts for gutter overflow, downpipe loss and roof pore retention (UNEP, 2007). Tank volume and roof area are considered as under QDC MP 4.2. A first flush device is also mandatory to discard the lower quality water that flows at the beginning of a rainfall event, which has been set at 15L (Queensland Government, 2007).

Daily end-use consumption values (Table 4) have been selected from Willis (2011), containing compiled results of monitoring conducted by the research team at a range of locations across

Table 3. Common input parameters for all scenarios.

\begin{tabular}{ll}
\hline Parameter & Value \\
\hline Historical rainfall data & $1993-2012$ \\
Roof area & $100 \mathrm{~m}^{2}$ \\
Tank volume & $5000 \mathrm{~L}$ \\
Initial volume & $0 \mathrm{~L}$ \\
First flush volume & $15 \mathrm{~L}$ \\
Runoff coefficient & 0.8 \\
\hline
\end{tabular}
GCC, with a sample total 411 homes. This is considered the best representation of water demand from typical the GCC resident. The relationship between total occupancy and consumption has been considered linear.

Table 4. Daily consumption parameters.

\begin{tabular}{ll}
\hline End-use & $\mathbf{L} / \mathbf{p} / \mathbf{d}$ \\
\hline Clothes Washer & 30.1 \\
Toilet Cistern & 23.0 \\
Irrigation Stage 1 & 5.0 \\
Irrigation Stage 2 & 35.0 \\
\hline
\end{tabular}

For irrigation, Stage 1 and Stage 2 values were selected from upper and lower quartile consumption during monitoring, to average out at the $24.1 \mathrm{~L} / \mathrm{p} / \mathrm{d}$ of the overall sample over the 20 year period.

$\mathrm{NEC}$, as shown in Equation 2, is considered independent of water supply volume on any given day. A value of 0.047 $\mathrm{kWh} /$ day was employed, found from the average daily consumption of the 8 homes in the monitoring study exhibiting NEC.

\subsection{Standard and Alternate Scenarios}

Initially, a standard case was evaluated with 2.8 persons per household (GCCC, 2012a) and all end-uses plumbed in. Due to space limitations only the mean case from the 20 years modelled will be considered. This reveals the end-use energy intensity breakdown, as illustrated in Figure 3. Of total energy consumed, toilet flushing is the greatest consumer at $40 \%$ in only supplying $31 \%$ of water (when NEC is not included). When including NEC as a toilet related inefficiency, this jumps to $51 \%$. Contrastingly, irrigation events consume just $21 \%$ of energy to supply $28 \%$ of water in the average year.

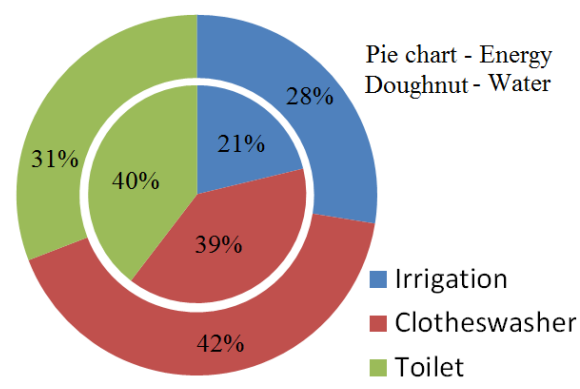

Figure 3. Proportion of water supplied per end-use (doughnut chart) and proportion of electricity consumed (pie chart).

The major optimisation question raised from the availability of the end-use energy intensities is under what circumstances would removing the least efficient end-uses (cistern flushes) result in a favourable economic and/or environmental outcome? To explore this, a 2.8 person household without toilet end-uses plumbed to rainwater supply was modelled. With NEC most commonly occurring due to cistern leaks, this was also omitted from the scenario. High and low occupancy cases were also considered, presented in Table 5. To put these differences in yield and energy consumption into perspective, costs for water, carbon and electricity have been included. 
Siems et al., Impact of energy intensity on the economic and environmental costs of rainwater tank systems

Table 5. Average annual water, energy, carbon and cost values under various IPWRTs scenarios.

\begin{tabular}{|c|c|c|c|c|c|c|c|c|c|}
\hline $\begin{array}{l}\text { Occupancy } \\
(\mathrm{p} / \mathrm{hh})\end{array}$ & $\begin{array}{l}\mathbf{N} \\
\mathbf{E} \\
\mathbf{C} \\
- \\
\end{array}$ & $\begin{array}{c}\text { Toilets } \\
\text { Plumbed } \\
- \\
\end{array}$ & $\begin{array}{l}\text { Water } \\
\text { Yield } \\
(\mathrm{kL}) \\
\end{array}$ & $\begin{array}{c}\text { Energy } \\
\text { Consumed } \\
(\mathbf{k W h}) \\
\end{array}$ & $\begin{array}{c}\text { Mains } \\
\text { Water } \\
\text { Saving } \\
(\$) \\
\end{array}$ & $\begin{array}{c}\text { Electricit } \\
\text { y Cost } \\
(\$) \\
\end{array}$ & $\begin{array}{l}\text { Carbon } \\
\text { Emitted } \\
(\mathrm{kg} \mathrm{CO})\end{array}$ & $\begin{array}{c}\text { Current } \\
\text { Carbon } \\
\text { Cost } \\
(\$) \\
\end{array}$ & $\begin{array}{c}\text { Social } \\
\text { Carbon } \\
\text { Cost } \\
(\$) \\
\end{array}$ \\
\hline 2.8 & $\checkmark$ & $\sqrt{ }$ & 57.3 & 93.0 & 188.41 & 27.90 & 98.6 & 2.38 & 26.23 \\
\hline 2.8 & $x$ & $\checkmark$ & 57.3 & 75.8 & 188.41 & 22.75 & 80.4 & 1.94 & 21.38 \\
\hline 2.8 & $x$ & $x$ & 46.5 & 53.5 & 152.92 & 16.06 & 56.7 & 1.36 & 15.09 \\
\hline 5 & $\checkmark$ & $\checkmark$ & 69.1 & 110.1 & 227.35 & 33.02 & 116.7 & 2.82 & 31.03 \\
\hline 5 & $x$ & $x$ & 60.9 & 70.6 & 200.22 & 21.17 & 74.8 & 1.81 & 19.89 \\
\hline 1 & $\checkmark$ & $\checkmark$ & 27.5 & 53.3 & 90.55 & 16.00 & 56.5 & 1.37 & 15.04 \\
\hline 1 & $x$ & $x$ & 19.6 & 22.5 & 64.46 & 6.75 & 23.9 & 0.58 & 6.34 \\
\hline
\end{tabular}

$\mathrm{CO}_{2}$-e/kWh (DERM, 2007), Current Carbon Cost \$24.15/tonne, Social Carbon Cost \$266/tonne (Johnson and Hope, 2012).

In the standard 2.8 person household, removing toilet end-uses and associated NEC consumption is predicted to decrease water yield by $18.9 \%$, while energy consumption and carbon emissions fall by a much larger $42.4 \%$. However, due to the much greater value of water in GCC $(\$ 3.29 / \mathrm{kL})$ relative to electricity $(\$ 0.29 / \mathrm{kWh})$, on initial analysis this does not present a potential source of economic optimisation for the homeowner. This change, based only on operating costs, would leave homeowners $\$ 23.64$ out of pocket annually.

This situation may change significantly when plumbing costs are considered. Binney and Macintyre (2012) report that the average cost of installing plumbing for IPRWTs in Queensland is \$1,400. If just (\$470) 33.8\% of this cost was alleviated through not plumbing in toilet cisterns to rainwater supply, this would be a better cost option (considering a 20 year life span and neglecting inflation). This is plausible given that many dwellings have up to 4 toilet cisterns, with only one clothes washer supply line and one rainwater tap. This should be taken into account by potential retrofitters and new home builders.

As occupancy increases, it becomes more worthwhile to only plumb in irrigation and clothes washers, due to rainwater yield falling by a smaller amount (i.e. without toilet demand available tank water is still consumed by the remaining end-uses). Conversely, in low occupancy houses rainwater yields drops much further, by an amount closer to the omitted toilet demand, making this less economically worthwhile.

For environmental impact analysis the carbon dioxide emissions have been calculated. For homeowners this is not a direct concern, with carbon prices are currently passed onto through electricity tariffs. However, from a community perspective it is worth considering the 'social cost of carbon'. A recent study conducted by researchers from the University of Cambridge (Johnson and Hope, 2012) places this cost to the community as high as $\$ 266 /$ tonne (in the US).

Kenway (2008) found that central potable water supply has an energy intensity of just $0.21 \mathrm{kWh} / \mathrm{kL}$ in GCC. Comparing central and rainwater supplies, the standard home with a yield of $57.3 \mathrm{~kL}$ would emit $\$ 26.23$ worth of carbon using rainwater compared to just $\$ 3.40$ if central water was consumed instead. Thus, if this social cost of carbon is included, rainwater tanks are clearly not environmentally friendly when water is available through central pipelines from surface catchment. From an end-use standpoint, including this cost would make omitting cistern flushes from rainwater supply a significantly more favourable option, both economically and environmentally.

\section{CONCLUSIONS}

This end-use level modelling has determined the expected average annual energy consumptions for IPRWTs under a range of scenarios in GCC. A standard 2.8 person household is predicted to save $57.3 \mathrm{~kL}$ of water each year, but emit $98.6 \mathrm{~kg}$ of carbon dioxide in supplying this rainwater to end-uses in the home.

The end-use study which informs the modelling in this paper determined that refilling toilet cisterns uses significantly more energy than other end uses. The impact of not using rainwater through toilet cisterns was found to reduce the value of water yields by more than the value of reduced energy consumption when based on direct operational costs. However, preliminary analysis indicated that when plumbing costs and environmental impacts are considered, not plumbing in this end-use to IPRWTs in retrofit and new homes would be economically and environmentally favourable.

Future research, with the goal of model refinement, will investigate in more detail the root cause of NEC and how end-use usage habits vary under different climatic conditions. 
Siems et al., Impact of energy intensity on the economic and environmental costs of rainwater tank systems

\section{ACKNOWLEDGMENTS}

Special thanks to the Smart Meter Information Portal developed and supported by the e-Research Services Team at Griffith University, as well as Dr Ruben Gonzalez and Mr Steven Tucker from Griffith School of ICT for their assistance in setting up an FTP. Also thanks to Reza Talebpour for his outstanding contribution to the IPRWTs monitoring study.

\section{REFERENCES}

Aquacraft (1997). Trace Wizard. Boulder, Colorado.

Beal, C., Stewart, R., Huang, T. \& Rey, E. (2011). SEQ residential end use study. Water: Journal of Australian Water Association, 38(1), 80-84.

Beal C., Gardner, T., Sharma, A., Chong, M. (2012) A desktop analysis of potable water savings from internally plumbed rainwater tanks in south-east Queensland, Australia. Water Resources Management, 26 (6), 1577-1590, doi.org/10.1007/s11269-011-9973-0.

Binney, J. \& Macintyre, A. (2012). Domestic rainwater tanks in Queensland: cost effectiveness and impacts on housing costs. A report prepared for Master Builders Queensland. Brisbane, Australia.

CSIRO (2011a). Climate change: science and solutions for Australia, Collingwood, CSIRO Publishing.

CSIRO. (2011b). The Millennium Drought and 2010/11 Floods Factsheet. South Eastern Australian Climate Initiative. Available: www.seaci.org/publications/documents/SEACI2Reports/SEACI2 Factsheet2of4 WEB 110714.pdf.

Cunio, L. N. \& Sproul, A. B. (Year) Published. Low Energy Pumping Systems for Rainwater Tanks. Solar09, the 47th ANZES Annual Conference, 2009 Townsville.

Department of Climate Change (2009). Climate Change Risks to Australia's Coasts: A First Pass National Assessment.

Department of Environment and Resource Management. (2007). ecoBiz Queensland tables of conversions and units. Available: http://www.derm.qld.gov.au/register/p01295al.pdf.

Department of Infrastructure and Planning (2009). South East Queensland Regional Plan 2009-2031. Department of Infrastructure and Planning, Queensland Government.

Flower, D. J. M., Mitchell, V. G. \& Codner, G. (2007). Urban Water Systems: Drivers of Climate Change? Melbourne: Institute for Sustainable Water Resources and Department of Civil Engineering, Monash University.

Gold Coast City Council (2012a). Population and Dwelling Profile. Office of Economic and Statistical Research, Queensland Treasury and Trade.

Gold Coast City Council. (2012b). Water and wastewater pricing 2012-13. Available: http://www.goldcoast.qld.gov.au/documents/bf/water-and-wastewater-pricing-2012-13.pdf [Accessed 22/03/2013].

Hatton, T., Cork, S., Joy, P. H. R., Kanowski, P., Mackay, R., McKenzie, N., Ward, T. \& Wienecke, B. (2011). State of the Environment 2011. Canberra: The Department of Sustainability, Environment, Water, Population and Communities.

Huang, A. \& Stewart, R. A. (2011). Experimental study on meter registration accuracy at low flow rates and benefits of UFR implementation. Centre for Infrastructure Engineering and Management Technical Report CIEM/2011/R03, Griffith University.

Johnson, L. \& Hope, C. (2012). The social cost of carbon in U.S. regulatory impact analyses: an introduction and critique. Journal of Environmental Studies and Sciences, 2(3), 205-221.

Kenway, S. (2008). Energy use in the provision and consumption of urban water in Australia and New Zealand. Water for a Healthy Country National Research Flagship. CSIRO.

MathWorks (2012). MATLAB. Natick, Massachusetts, U.S.A.

Organisation for Economic Co-operation and Development (2006). OECD Key Environmental Indicators. Paris, France: OECD Environment Directorate.

Pink, B. (2012). Year Book Australia. Canberra, Australia: Australian Bureau of Statistics.

Queensland Government (2007). Queensland Development Code Mandatory Part 4.2 - Water Savings Targets. Department of Housing and Public Works.

Retamal, M., Glassmire, J., Abeysuriya, K., Turner, A. \& White, S. (2009). The Water-Energy Nexus: Investigation into the Energy Implications of Household Rainwater Systems. Sydney: Institute for Sustainable Futures, University of Technology.

Siems, R., Sahin, O., Talebpour, M., Stewart, R. \& Hopewell, M. (2013) Published. Energy intensity of decentralised water supply systems utilised in addressing water shortages. 8th International Conference of the European Water Resources Association, 2013 Porto, Portugal.

Stewart, R., (2011). Verifying the end use potable water savings from contemporary residential water supply schemes, National Water Commission Waterlines Report No. 61, Australian Government, Canberra.

Talebpour, M. R., Stewart, R. A., Beal, C., Dowling, B., Sharma, A. \& Fane, S. (2011). Rainwater Tank End Usage and Energy Demand: A Pilot Study. Water: Journal of Australian Water Association, 38(1), 97-101.

UNEP. (2007). Rainwater Harvesting Technical Sheets. Available: www.unep.org/themes/Freshwater/PDF/RWH\%20technical\%20sheets.pdf].

Willis, R. (2011). Domestic Water End Use Study: An Investigation of the Water Savings Attributed to Demand Management Strategies and Dual Reticulated Recycled Water Systems. PhD, Griffith University. 